\title{
Factors associated with clinical outcomes among neonates admitted with acute bilirubin and hypoxic-ischaemic encephalopathies at a tertiary hospital in south-west Nigeria
}

\author{
Olusoga Babatunde Ogunfowora (D), Tinuade Adetutu Ogunlesi* and Victor Ayodeji Ayeni
}

Department of Paediatrics, Olabisi Onabanjo University Teaching Hospital, Sagamu, Nigeria

*Corresponding author, email: tinuade_ogunlesi@yahoo.co.uk

Background: Babies who are delivered outside hospital are most at risk of serious illnesses such as perinatal asphyxia and severe hyperbilirubinaemia. These conditions are major contributors to neonatal mortalities in resource-poor settings.

Objective: To explore the relationship between pre-admission and intra-facility care and immediate outcomes among neonates with acute bilirubin and hypoxic-ischaemic encephalopathies.

Methods: Using a retrospective design, the outcome of outborn babies with acute bilirubin encephalopathy (ABE) and hypoxicischaemic encephalopathy (HIE) were studied in a Nigerian hospital between 2012 and 2016.

Results: A total of 40 and 80 babies with $A B E$ and HIE were studied. Among babies with $A B E, 67.5 \%$ arrived at the hospital on selfreferral and of the babies with official referral, only $61.5 \%$ had had a serum bilirubin check prior to referral. Among the babies with $A B E, 25.0 \%$ had both social and facility-related challenges, $45.0 \%$ had only facility-related challenges and $20.0 \%$ had only social challenges. All the babies with ABE who died had either social or facility-related challenges. For the babies with $\mathrm{HIE}, 56.2 \%$ came on self-referral while $70 \%$ received no care prior to presentation at the hospital. Some $40 \%$ of babies with HIE had both social and facility-related challenges while $12.5 \%$ had only facility-related challenges. None of the babies who died presented early. Comparable proportions of babies who died or survived had social challenges and facility-related challenges.

Conclusion: Most of the outborn babies with HIE and ABE who arrived at the hospital on self-referral and facility-based care were hindered by social issues and facility-related challenges.

Keywords: Asphyxia, health system, hypoxic-ischaemic encephalopathy, newborn, referral, severe hyperbilirubinaemia

\section{Introduction}

Although significant improvement has been made in under-five mortality in the developing world over the last decade, the bulk of the progress made so far has been in terms of infant mortality rather than neonatal mortality. ${ }^{1}$ The major challenge with neonatal survival remains poor intra-partum and immediate postnatal care. ${ }^{2,3}$ This scenario is compounded by the fact that most deliveries, in the developing world, take place outside the hospital ${ }^{4}$ and such babies make contact with the health facilities only after developing some sort of severe illnesses. Therefore, as well as the complications of preterm and low birthweight deliveries, perinatal asphyxia, infections and hyperbilirubinaemia have frequently been reported as the leading causes of neonatal admissions and mortalities in the resource-limited areas of the world. ${ }^{5-12}$ The odds of mortality among babies with these conditions have been variously reported to be higher among outborn babies. $6,7,13-15$

On a general note, studies in the developing world have suggested that babies delivered outside the hospital are at worse risk of complications such as hypoxic-ischaemic encephalopathy (HIE), ${ }^{13,16}$ and acute bilirubin encephalopathy (ABE). ${ }^{15,17}$ This higher tendency for complications occurs for various reasons ranging from inappropriate and ineffective home care, and delay in seeking effective care outside home, to seeking care at inappropriate places and non-availability of desired quality care, even at the appropriate health facilities. ${ }^{18-20}$ In most parts of low and middle-income countries (LMICs), health care is mostly financed by out-of-pocket payment by families. Therefore, any factor that affects the financial strength of families has a major influence on the quality of health care that severely ill babies in such families can access. Therefore, this study proposes to highlight the effect of pre-hospital care as well as within-facility adverse events (caused by social and facility-related infrastructural or organisational impediments) on the eventual outcome of hospitalised babies with serious illnesses, as the findings may suggest specific areas that need specific interventions.

The objective of this study was to explore the relationship between pre-admission and intra-facility care and immediate outcomes among neonates with acute bilirubin and hypoxicischaemic encephalopathies at the Olabisi Onabanjo University Teaching Hospital (OOUTH), Sagamu, Nigeria.

\section{Materials and methods}

This was a retrospective study covering the period between January 2012 and December 2016. The study setting was the Neonatal Ward of the OOUTH, Sagamu, Ogun State, Nigeria, which has provided specialised paediatric care for newborn babies delivered within the hospital as well as those referred from other facilities within and outside Sagamu since 1989.

OOUTH receives babies referred from other government-owned health facilities such as primary health centres and general hospitals as well as privately owned hospitals within Sagamu, from other parts of Ogun State and from adjoining parts of Lagos, Ondo and Edo States. In addition, some babies are brought directly from homes without previously traversing other health facilities. 
The pattern of neonatal admissions and mortalities had been described earlier; perinatal asphyxia, infections and jaundice played leading roles in neonatal morbidity and mortality in Sagamu. ${ }^{21}$ Hypoxic-ischaemic encephalopathy is a major complication of perinatal asphyxia, which is associated with remarkable immediate mortality or survival with a variety of neurological deficits. ${ }^{22}$ Similarly, bilirubin encephalopathy is the most important complication of hyperbilirubinaemia in the newborn, which is associated with mortality or survival with neurological deficits. $^{15}$ Therefore, acute bilirubin encephalopathy and hypoxicischaemic encephalopathy were specifically studied as prototypes of serious neonatal illnesses in this study.

Institutional ethical clearance for the study was obtained from the Health and Research Ethics Committee of Olabisi Onabanjo University Teaching Hospital, Sagamu, Nigeria (certificate number OOUTH/HREC/190/2017).

The hospital records of referred neonates aged between birth and 28 days with a diagnosis of (i) acute bilirubin encephalopathy $(\mathrm{ABE})$ or (ii) hypoxic-ischaemic encephalopathy (HIE) were retrieved from the Health Information Management Unit of the hospital. Only case files with complete data (according to the details required to be captured in the study proforma) were included in the study. Going by the existing pattern of admissions for these clinical conditions, the babies were recruited from the ward's admissions register in the ratio of 1 to 2 for $A B E$ and HIE respectively. ABE was defined using the criteria spelt out in the BIND scoring system (scoring of mental status, muscle tone and cry and scores of 2-3, 4-6 and 7-9 are graded mild, moderate and severe). ${ }^{23}$ HIE was defined according to the Sarnat and Sarnat criteria (using loss of consciousness, spontaneous activity, posture, tone, suck reflex, Moro reflex and pupillary action with classification into normal, mild, moderate and severe). ${ }^{24}$ The two scoring systems are included in the routine management protocol for these clinical conditions and are ordinarily applied to every baby with the respective diagnosis.

Using a data capture sheet, the dates of admission and hospital numbers of the subjects were retrieved. The data recorded for each baby included the age at presentation (in hours), sex, estimated gestational age at birth (if known), bodyweight at presentation, age and highest education and present occupation of parents, maternal parity, details of labour and delivery history to include the place and mode of delivery. The socioeconomic status of the family was determined using the parental highest education and present occupation according to Ogunlesi's model. ${ }^{25}$ The socioeconomic classes were described as Class I (highest) to Class V (lowest). Other data included details of referral (self- or official), clinical disorders prompting referral, details of care accessed (places visited and specific type of care offered) prior to arrival at OOUTH and outcome (and duration) of hospitalisation.

Social and facility-related impediments (infrastructural and organisational) to the management of each baby were searched for and recorded. ${ }^{26}$

The results of relevant laboratory investigations conducted at presentation were also extracted; these included serum total bilirubin, haematocrit and random blood glucose.

The outcome variables included immediate outcome of hospitalisation (discharge, death, premature discharge against medical advice) and the duration of hospitalisation.

\section{Data management}

The data were managed using SPSS version 21.0 statistical software (IBM Corp, Armonk, NY, USA). The data were analysed using simple descriptive and inferential statistics. The mean values were compared using Student's t-test while proportions were compared using Pearson's chi-square test and Fisher's exact test as necessary. Statistical significance was determined by $p$ values less than 0.05 .

\section{Results}

\section{Acute bilirubin encephalopathy (ABE)}

The 40 babies with $A B E$ were aged between 72 and 264 hours with the mean (SD) of 141.6 (39.5) hours. The mean (SD) estimated gestational age (EGA) was 38.2 (1.8) weeks with a range of 34-41 weeks while the mean (SD) bodyweight was $2.6(0.5) \mathrm{kg}$ with a range of $1.5-3.6 \mathrm{~kg}$. The duration of illness prior to presentation ranged between 18 and 144 hours with a mean (SD) of 68.2 (31.7) hours.

Table 1 shows that none of the babies was aged less than 72 hours at presentation while $30(75.0 \%)$ and $10(25.0 \%)$ babies were aged $72-144$ hours and $>144$ hours respectively. These babies comprised 31 (77.5\%) males, 33 (82.5\%) term babies, 27 (67.5\%) weighing $\geq 2.5 \mathrm{~kg}$, and $26(65.0 \%)$ delivered at orthodox facilities.

\section{Family characteristics}

Maternal age was $<20$ years, $20-35$ years and $>35$ years among 2 (5.0\%), $30(75.0 \%)$ and $8(20.0 \%)$ respectively, while $8(20.0 \%)$ and $32(80.0 \%)$ were primiparous and multiparous respectively (Table 1). Thirty-three (82.5\%) of the mothers and $26(65.0 \%)$ of the fathers had low education while $32(80.0 \%)$ belonged to the lower socioeconomic classes IV and V.

\section{Pattern of community-based care and intra-facility care}

Only 6 (15.0\%) babies presented within 24 hours of the onset of illness while the duration of illness prior to presentation was 25 72 hours and $>72$ hours among $26(65.0 \%)$ and $8(20.0 \%)$ babies respectively (Table 1 ). Fifteen $(37.5 \%)$ babies presented early ( $\leq$ 48 hours) while the remaining $25(62.5 \%)$ presented late (> 48 hours). Three-quarters of the babies (30/40) used home remedies (medications and herbal mixtures) prior to presentation.

Only 13 (32.5\%) had official referral from other facilities and of these 13 babies, only $8(61.5 \%)$ had blood tests for total serum bilirubin prior to referral. At presentation, the values of TSB were classified as $20-25 \mathrm{mg} / \mathrm{dl}, 26-30 \mathrm{mg} / \mathrm{dl}$ and $>30 \mathrm{mg} / \mathrm{dl}$ among 7 (17.5\%), 8 (20.0\%) and 25 (62.5\%) babies respectively. Overall, $28(70.0 \%)$ babies had exchange blood transfusion (EBT). Among the 28 babies who had EBT, the interval between admission and EBT was 3-6 hours, 7-15 hours and $>15$ hours among 15 (53.5\%), 12 (42.9\%) and 1 (3.6\%) respectively. In addition, $23(82.1 \%)$ babies had only one session of EBT while $5(17.9 \%)$ had two sessions. Other co-morbidities present at the point of admission included hypothermia (4;10.0\%), hyperthermia $(31 ; 77.5 \%)$, hypoglycaemia $(9 ; 22.5 \%)$ and severe anaemia $(27 ; 67.5 \%)$.

\section{Challenges of intra-facility care}

Eighteen (45.0\%) had social problems while facility-related challenges were recorded among $28(70.0 \%)$ babies as detailed in Table 1. 
Table 1: Characteristics of the babies with acute bilirubin and hypoxic-ischaemic encephalopathies

\begin{tabular}{|c|c|c|c|c|c|}
\hline \multirow[b]{2}{*}{ Parameters } & & \multicolumn{2}{|c|}{$\mathrm{ABE}$} & \multicolumn{2}{|c|}{ HIE } \\
\hline & & $n$ & $\%$ & $n$ & $\%$ \\
\hline \multirow[t]{2}{*}{ Sex } & Male & 31 & 77.5 & 38 & 47.5 \\
\hline & Female & 9 & 22.5 & 42 & 52.5 \\
\hline \multirow[t]{2}{*}{ Maturity } & Preterm & 7 & 17.5 & 3 & 3.8 \\
\hline & Term & 33 & 82.5 & 77 & 96.2 \\
\hline \multirow[t]{2}{*}{ Orthodox POD } & Yes & 26 & 65.0 & 49 & 61.3 \\
\hline & No & 14 & 35.0 & 31 & 38.7 \\
\hline \multirow[t]{2}{*}{ Type of referral } & Official & 13 & 32.5 & 35 & 43.7 \\
\hline & Self- & 27 & 67.5 & 45 & 56.3 \\
\hline \multirow{2}{*}{$\begin{array}{l}\text { Maternal } \\
\text { education }\end{array}$} & Low $^{a}$ & 33 & 82.5 & 48 & 60.0 \\
\hline & $\mathrm{High}^{\mathrm{b}}$ & 7 & 17.5 & 32 & 40.0 \\
\hline \multirow{2}{*}{$\begin{array}{l}\text { Paternal } \\
\text { education }\end{array}$} & Low $^{a}$ & 26 & 65.0 & 40 & 50.0 \\
\hline & $\mathrm{High}^{\mathrm{b}}$ & 14 & 35.0 & 40 & 50.0 \\
\hline \multirow[t]{3}{*}{$\mathrm{SES}^{\mathrm{c}}$} & III & 8 & 20.0 & 22 & 27.5 \\
\hline & IV & 24 & 60.0 & 44 & 55.0 \\
\hline & V & 8 & 20.0 & 14 & 17.5 \\
\hline \multirow{6}{*}{$\begin{array}{l}\text { Details of social } \\
\text { issues }\end{array}$} & Poor finances & 10 & 25.0 & 13 & 16.3 \\
\hline & DAMA threats ${ }^{d}$ & 4 & 10.0 & 3 & 3.7 \\
\hline & $\begin{array}{l}\text { Separated } \\
\text { parents }\end{array}$ & 2 & 5.0 & 5 & 6.2 \\
\hline & $\begin{array}{l}\text { Unmarried } \\
\text { parents }\end{array}$ & 2 & 5.0 & 6 & 7.5 \\
\hline & $\begin{array}{l}\text { Polygamous } \\
\text { family setting }\end{array}$ & 0 & 0.0 & 16 & 20.0 \\
\hline & None & 22 & 55.0 & 40 & 50.0 \\
\hline \multirow{10}{*}{$\begin{array}{l}\text { Details of intra- } \\
\text { facility } \\
\text { challenges }\end{array}$} & $\begin{array}{l}\text { No blood in the } \\
\text { laboratory }\end{array}$ & 10 & 25.0 & NA & - \\
\hline & $\begin{array}{l}\text { Parents not } \\
\text { available to pay }\end{array}$ & 1 & 2.5 & NA & - \\
\hline & Laboratory delays & NA & - & 15 & 18.7 \\
\hline & $\begin{array}{l}\text { Lack of funds for } \\
\text { drugs }\end{array}$ & NA & - & 5 & 6.3 \\
\hline & $\begin{array}{l}\text { Lack of funds for } \\
\text { investigations }\end{array}$ & NA & - & 10 & 12.5 \\
\hline & Lack of electricity & 4 & 10.0 & 10 & 12.5 \\
\hline & $\begin{array}{l}\text { Materials for EBT } \\
\text { out of stock }\end{array}$ & 2 & 5.0 & NA & - \\
\hline & $\begin{array}{l}\text { No EBT due to } \\
\text { poor clinical state }\end{array}$ & 6 & 15.0 & NA & - \\
\hline & $\begin{array}{l}\text { Cannulation for } \\
\text { EBT not possible }\end{array}$ & 5 & 12.5 & NA & - \\
\hline & None & 12 & 30.0 & 37 & 46.3 \\
\hline \multirow[t]{4}{*}{ Problem of care } & Social issues only & 8 & 20.0 & 13 & 16.3 \\
\hline & $\begin{array}{l}\text { Intra-facility } \\
\text { issues only }\end{array}$ & 18 & 45.0 & 10 & 12.5 \\
\hline & $\begin{array}{l}\text { Both social and } \\
\text { intra-facility } \\
\text { issues }\end{array}$ & 10 & 25.0 & 32 & 40.0 \\
\hline & None & 4 & 10.0 & 25 & 31.2 \\
\hline \multirow{2}{*}{$\begin{array}{l}\text { Duration of } \\
\text { admission }\end{array}$} & $>168$ hours & 16 & 40.0 & 61 & 76.3 \\
\hline & $\leq 168$ hours & 24 & 60.0 & 19 & 23.7 \\
\hline
\end{tabular}

ABE: acute bilirubin encephalopathy; HIE: hypoxic-ischaemic encephalopathy

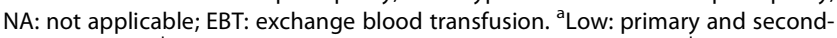

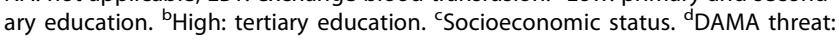
disruption of clinical care due to attempts to discharge baby against medical discharge
Overall, 10 (25.0\%) babies had both social and facility-related challenges while only $4(10.0 \%)$ had neither social nor facilityrelated challenges of care.

\section{Immediate outcome of care}

Nineteen (47.5\%) were discharged home, 12 (30.0\%) died during admission while the remaining $9(22.5 \%)$ were prematurely discharged against medical advice. The duration of hospitalisation ranged from 3 to 1128 hours with a median of 132 hours. Sixteen (40.0\%) babies stayed less than 168 hours (a week) while 33 $(82.5 \%)$ stayed longer than 336 hours (two weeks). As seen in Table 2, a significantly higher proportion of babies who died did not have EBT $(p=0.001)$. A higher proportion of babies who died had facility-related challenges but without statistical significance. Similarly, a higher proportion of babies who died had official referral and had TSB check prior to referral to hospital but without statistical significance in both instances. Interestingly, all the babies who died had either social or facilityrelated challenges whereas $10.5 \%$ of those who were discharged did not have either social or facility-related challenges.

\section{Hypoxic-ischaemic encephalopathy}

The 80 babies with HIE had a mean (SD) age at presentation of 27.1 (16.6) hours with a range of 2-62 hours. The mean (SD) estimated gestational age (EGA) was 38.3 (1.2) weeks with a range of 36-41 weeks. The bodyweight ranged from $2.1 \mathrm{~kg}$ to $3.9 \mathrm{~kg}$ with a mean (SD) of $2.8(0.4) \mathrm{kg}$. The mean (SD) duration of illness prior to presentation at the hospital was 27.1 (16.6) hours.

The distribution of the babies according to the age at presentation showed that $14(17.5 \%), 28(35.0 \%), 29(36.2 \%)$ and 9 (11.3\%) were aged $<12$ hours, $12-24$ hours, $25-48$ hours and $>48$ hours respectively. These babies compromised 38 (47.5\%) males, $77(96.2 \%)$ term babies, 66 (82.3\%) weighing $\geq 2.5 \mathrm{~kg}$ and $49(61.3 \%)$ babies were delivered at orthodox facilities. The modes of delivery included spontaneous vertex method (62; 77.5\%), ventouse $(8 ; 10.0 \%)$, Caesarean section $(5 ; 6.3 \%)$ and assisted breech $(5 ; 6.3 \%)$ respectively.

\section{Family characteristics}

Maternal age was $<20$ years, $20-35$ years and $>35$ years among $2(3.7 \%), 50(62.5 \%)$ and $27(33.8 \%)$ respectively. Twenty-four $(30.0 \%)$ mothers were primiparous while $48(60.0 \%)$ of the mothers and $40(50.0 \%)$ of the fathers had low education. Fifty-eight $(72.5 \%)$ belonged to the lower socioeconomic classes IV and V.

Pattern of community-based care and intra-facility care Eleven $(13.7 \%)$ babies presented early ( $\leq 6$ hours) while the severity of HIE was distributed as follows: Stage I (12; 15.0\%), Stage II (59; 73.8\%); Stage III (9; 11.2\%). Some 70\% (56/80) received no care prior to presentation at the hospital while 22 (27.5\%) and 2 (2.5\%) had administration of unknown injections and hot water massage respectively prior to presentation.

Thirty-five (43.8\%) had official referral from other facilities. Other co-morbidities present at the point of admission included hypothermia $(6 ; 7.5 \%)$, hyperthermia $(53 ; 66.3 \%)$, hypoglycaemia $(23 ; 28.8 \%)$, hyperglycaemia $(8 ; 10.0 \%)$ and severe anaemia $(23$; $28.8 \%)$.

\section{Challenges of intra-facility care}

Table 1 shows that half of the babies had social problems while $43(53.8 \%)$ babies had facility-related challenges. 
Table 2: Factors associated with immediate outcome of 31 babies with $\mathrm{ABE}^{*}$

\begin{tabular}{|c|c|c|c|c|}
\hline Parameters & & Died $(n=12)$ & Discharged $(n=19)$ & Statistics \\
\hline \multirow[t]{2}{*}{ Orthodox POD } & Yes & $8(66.7)$ & $11(57.9)$ & $x^{2}=0.241^{b}$ \\
\hline & No & $4(33.3)$ & $8(42.1)$ & $p=0.624$ \\
\hline TSB checked before referral & Yes & $3(25.0)$ & $3(18.8)$ & $p=0.531$ \\
\hline \multirow[t]{2}{*}{ Delay } & Early $<48$ hours & $5(41.7)$ & $7(36.8)$ & $x^{2}=0.072$ \\
\hline & Late $>48$ hours & $7(58.3)$ & $12(63.2)$ & $p=0.788$ \\
\hline \multirow[t]{2}{*}{ Type of referral } & Official & $5(41.7)$ & $4(21.0)$ & $x^{2}=1.494^{b}$ \\
\hline & Self- & $7(58.3)$ & $15(79.0)$ & $p=0.222$ \\
\hline \multirow[t]{2}{*}{ Maternal education } & High & $2(16.7)$ & $2(10.5)$ & $x^{2}=0.241^{b}$ \\
\hline & Low & $10(62.3)$ & $17(89.5)$ & $p=0.623$ \\
\hline \multirow[t]{2}{*}{ Paternal education } & High & $6(50.0)$ & $4(21.0)$ & $x^{2}=2.793$ \\
\hline & Low & $6(50.0)$ & $15(79.0)$ & $p=0.095$ \\
\hline Home remedy use & Yes & $7(58.3)$ & $16(84.2)$ & $p=0.112$ \\
\hline \multirow[t]{2}{*}{ Social issue } & Absent & $7(58.3)$ & $11(57.9)$ & $x^{2}=0.001$ \\
\hline & Present & $5(41.7)$ & $8(42.1)$ & $p=0.981$ \\
\hline \multirow[t]{2}{*}{ Intra-facility challenges } & Absent & $1(8.3)$ & $4(21.0)$ & $x^{2}=0.951^{b}$ \\
\hline & Present & $11(91.7)$ & $15(79.0)$ & $p=0.329$ \\
\hline \multirow[t]{4}{*}{ Issues } & Both social and intra-facility & $4(33.3)$ & $6(31.6)$ & \\
\hline & Intra-facility only & $7(58.4)$ & $9(47.4)$ & $x^{2}=1.478$ \\
\hline & None & $0(0.0)$ & $2(10.5)$ & $p=0.537$ \\
\hline & Social only & $1(8.3)$ & $2(10.5)$ & \\
\hline \multirow[t]{3}{*}{$\mathrm{SES}^{\mathrm{a}}$} & III & $3(25.0)$ & $2(10.5)$ & \\
\hline & IV & $5(41.7)$ & $13(68.5)$ & $x^{2}=2.290^{b}$ \\
\hline & V & $4(33.3)$ & $4(21.0)$ & $p=0.318$ \\
\hline Intervention & EBT & $4(33.3)$ & $17(89.5)$ & $x^{2}=10.922^{b}$ \\
\hline
\end{tabular}

*Nine babies with DAMA outcome were excluded.

${ }^{\text {a }}$ Socio-economic status

'Yates' correction applied.

Overall, $32(40.0 \%)$ babies had both social and facility-related challenges, while $25(31.2 \%)$ had neither social nor facilityrelated challenges of care.

\section{Immediate outcome of care}

Sixty-one (76.3\%) babies were discharged home, 16 (20.0\%) died during the admission while the remaining $3(3.7 \%)$ were prematurely discharged against medical advice. The mean (SD) duration of hospitalisation was 244.4 (140.3) hours with a range from 6 to 504 hours. Nineteen (23.7\%) babies stayed less than 168 hours (a week) while 53 (66.3\%) stayed longer than 336 hours (two weeks). In Table 3, it may be seen that significantly higher proportions of babies who died were delivered at orthodox facilities $(p=0.04)$ and had official referral $(p<0.001)$. None of the babies who died presented early. Comparable proportions of babies who died or survived had social challenges and facilityrelated challenges but without statistical significance.

\section{Discussion}

The present study showed that about one-third of babies with ABE and one-fifth of babies with HIE died in the course of hospitalisation. The mortality rate in perinatal asphyxia is reportedly high as previously documented. ${ }^{27,28}$ None of the babies who died from HIE presented early at OOUTH but higher proportions of these babies had orthodox facility delivery and official referral to OOUTH. For babies with ABE, death was strongly associated with inability to perform EBT. Social and facility-related challenges were recorded among the babies in both arms of the study but to variable extents.

Close to two-thirds of the babies with ABE and HIE were delivered at orthodox health facilities (comprising government and privately owned facilities) where the standard of care and quality of services are expected to be fairly regulated. Therefore, the occurrence of $\mathrm{ABE}$ and HIE in these babies may reflect a poorer standard of care (compared with the recommended quality of care for each condition) or late presentation in compromised state at those facilities. It is not strange in this setting for a parturient to first seek obstetric care during labour at non-orthodox facilities (traditional and spiritual birth homes) and thereafter to resort to orthodox facilities when emergencies occur or progress could not be made, by which time foetal compromise might have occurred. ${ }^{16}$ Despite the pressure for early discharge from the nursery, babies should be screened for the risk of significant hyperbilirubinaemia using the various recommended tools (such as the normogram for plotting six-hour serum bilirubin level as a predictor of severe hyperbilirubinaemia within the first week of life). ${ }^{29}$ Mothers should be taught how to check their babies for jaundice in bright light and be encouraged to seek care promptly when jaundice is detected. ${ }^{18}$

Low parental education and socioeconomic status were observed in most of the babies with ABE and HIE. Low education may fuel inability to recognise danger signs in babies and lack of understanding of the need to seek care. ${ }^{18}$ 
Table 3: Factors associated with immediate outcome of 77 babies with HIE*

\begin{tabular}{|c|c|c|c|c|}
\hline Parameters & & Died $(n=16)$ & Discharged $(n=61)$ & Statistics \\
\hline \multirow[t]{2}{*}{ Orthodox POD } & Yes & $3(18.8)$ & $28(45.9)$ & $x^{2}=4.208^{* *}$ \\
\hline & No & $13(81.2)$ & $33(54.1)$ & $p=0.04$ \\
\hline Type of referral & Self & $3(18.8)$ & $42(68.9)$ & $p<0.001$ \\
\hline \multirow[t]{2}{*}{ Delay } & Early $<6$ hours & $0(0.0)$ & $11(18.0)$ & Fisher's exact test $p=0.107$ \\
\hline & Late $>6$ hours & $16(100.0)$ & $50(82.0)$ & \\
\hline \multirow[t]{3}{*}{ Care prior to referral } & Hot water & $0(0.0)$ & $2(3.3)$ & \\
\hline & Injection & $10(62.5)$ & $10(16.4)$ & $x^{2}=13.064^{* *}$ \\
\hline & None & $6(37.5)$ & $49(80.3)$ & $p=0.001$ \\
\hline \multirow[t]{2}{*}{ Maternal education } & High & $3(18.8)$ & $26(42.6)$ & $x^{2}=3.334^{* *}$ \\
\hline & Low & $13(81.2)$ & $35(57.4)$ & $p=0.068$ \\
\hline Paternal education & High & $16(100.0)$ & $23(37.7)$ & Fisher's exact test \\
\hline \multirow[t]{2}{*}{ Social issues } & Absent & $10(62.5)$ & $27(44.3)$ & $x^{2}=1.069^{* *}$ \\
\hline & Present & $6(37.5)$ & $34(55.7)$ & $p=0.586$ \\
\hline \multirow[t]{2}{*}{ Intra-facility challenge } & Absent & $6(37.5)$ & $28(45.9)$ & $x^{2}=0.363$ \\
\hline & Present & $10(62.5)$ & $33(54.1)$ & $p=0.547$ \\
\hline \multirow[t]{4}{*}{ Issues } & Both social and intra-facility & $5(31.2)$ & $27(44.3)$ & \\
\hline & Intra-facility only & $5(31.2)$ & $5(8.2)$ & $x^{2}=19.151$ \\
\hline & None & $0(0.0)$ & $22(36.1)$ & $p<0.001$ \\
\hline & Social only & $6(37.4)$ & $7(11.4)$ & \\
\hline \multirow[t]{3}{*}{$\mathrm{SES}^{\mathrm{a}}$} & III & $3(18.8)$ & $19(31.1)$ & \\
\hline & IV & $10(62.4)$ & $31(50.9)$ & $x^{2}=1.069^{* *}$ \\
\hline & V & $3(18.8)$ & $11(18.0)$ & $p=0.586$ \\
\hline
\end{tabular}

*Three babies with DAMA outcome were excluded.

**Yates' correction applied.

${ }^{\text {a }}$ Socioeconomic status.

Most of the babies with ABE and HIE presented at the hospital late. Delay in presentation of referred babies with severe jaundice and severe asphyxia has been previously researched and the use of ineffective home remedies and low knowledge of the inherent dangers have been variously identified as reasons for such delays when babies have jaundice. ${ }^{18,19}$ It is attractive to postulate that, for babies delivered in non-orthodox facilities, accurate assessment at birth may not be possible, hence neurologically depressed babies may be missed until signs of severe illness such as convulsions and severe laboured breathing occur. This is a reason why the Helping Babies Breathe programme should be taken to hard-to-reach settings where many babies are actually delivered without any form of assessment and resuscitation at birth. ${ }^{30}$

The healthcare-seeking behaviour of the population studied is typified by the observation of self-referral among more than two-thirds of babies with $\mathrm{ABE}$ and more than half of the babies with HIE. This may imply that these critically ill babies were mostly brought straight from home or, in other instances, they could have presented at facilities which did not issue formal referral notes.

Where referral to a higher level of healthcare is indicated, it is imperative to carry out some basic immediate care to slow down the progression of the disease condition while in transit and limit the severity. For babies with severe asphyxia, basic pre-referral care may include adequate resuscitation, some form of ventilatory support and possibly administration of neuroprotective agents such as phenobarbitone, which is readily available and cheap. However, in this study, most of the babies with HIE had unidentified injections since there were no referral notes to provide such information. Rather, some babies reportedly had hot water fomentation. The latter is a harmful practice that has been documented in this part of the world..$^{31}$ Of the one-third of babies with ABE who had official referral, only $61.5 \%$ of them had blood estimation for total bilirubin prior to referral. A few had even had attempted exchange transfusion but this could not be continued for lack of expertise. $^{32}$ These lapses obviously show lack of guidelines for the management of these conditions at every level of care and should prompt frequent training. ${ }^{33}$

The severity of the conditions at the point of admission in most of the babies is instructive. Close to two-thirds (62.5\%) of the babies with ABE had TSB $>30 \mathrm{mg} / \mathrm{dl}$ while a comparable proportion of the babies with HIE had at least Stage II disease. These are similar to previous reports. ${ }^{22,34-36}$ These observations suggest that these diseases had progressed remarkably in severity by the time the babies reached hospital. This may be associated with delay in presentation as previously stated. Delay occurring at the lower levels of care may also be due to low knowledge and poor skills at that level as previously reported. $^{37,38}$ After arrival in the hospital, most babies with $A B E$ and who required exchange transfusion had the procedure not sooner than three hours later due to logistical problems. ${ }^{20}$

Studies describing the role of social and facility-related challenges in the quality of intra-facility care available to critically ill babies in the developing world are not available. Therefore, 
it is difficult making comparisons of the findings in this study with previous reports. About half of the babies with ABE and HIE had identifiable social challenges affecting intra-facility care. The challenges frequently relate to a polygamous family setting (which is usually characterised by large family size and the risk of low finances), marital conflicts between parents, parental separation, unmarried parents, single unsupported parenthood and lack of family supports. These social challenges dovetail into poor financial support for the care of the babies and, where the nursing personnel are inadequate, physical support during the care of the babies is also lacking.

Facility-related challenges were observed among $76 \%$ of babies with $\mathrm{ABE}$ and $53.8 \%$ of babies with HIE. These challenges comprised personnel, infrastructural and organisational problems, including staff shortage at every point of service, lack of electricity for clinical and laboratory procedures, lack of drugs in the pharmacy or lack of blood in the blood bank. The spillover effects of these shortcomings are many and, ultimately, adversely affect timely delivery of required clinical care to critically ill babies. Improved funding of the public health sector may solve many of the facility-related problems and ultimately the quality of care available in hospitals.

Death, as an outcome in this study, was associated with lack of exchange transfusion among babies with $A B E$ and all the babies with $A B E$ who died actually had impaired care from either social or facility-related challenges.

The retrospective and cross-sectional designs of the study with the attendant challenge of missing data, inability to establish causal effects and the small sample size are acknowledged as limitations to the study.

\section{Conclusion}

This study finds that pre-admission care, social factors and intrafacility care appear to have different relationships with the outcomes on ABE and HIE admissions. While it is intuitive that EBT would be significantly related to good outcomes in ABE admissions, several correlates of good outcomes in HIE admission (orthodox places of delivery, official referral, pre-admission administration of injections and higher parental education) were counter-intuitive. Considering this discrepancy and the study limitations, larger and better designed multi-centres studies are needed to validate the results of this study.

\section{Recommendations}

Reinvigoration of the health insurance scheme and improved funding of the health sector may ameliorate most of the problems identified. Stringent adherence to the tenets of the Integrated Management of Neonatal and Childhood Illnesses (IMNCI) has been advocated. This has been found to improve the quality of home care for newborn illnesses. ${ }^{39}$

Acknowledgement - The support of Mrs R.O. Omotayo of the Health Information Management Unit of OOUTH, Sagamu, Nigeria with the retrieval of hospital records is deeply appreciated.

Conflict of interest - No financial or non-financial benefits have been received or will be received from any party related directly or indirectly to the subject of this article.

Funding - None.
Authors' roles - OOB and OTA conceived and designed the study. OTA and AVA collected and analysed the data while OOB and OTA interpreted the data. The manuscript was drafted by OTA while $O O B$ did the literature search and review. All the authors contributed to the intellectual content of the manuscript.

\section{ORCID}

Olusoga Babatunde Ogunfowora (D) http://orcid.org/0000-00026143-6452

\section{References}

1. UNICEF, WHO, World Bank, UN-DESA Population Division. Levels and trends in child mortality 2015. Available from: www.who.int/ maternal_child_adolescents/documents/levels_trends_child-mortality_ 2015/en/

2. Lawn JE, Kerber K, Enweronu-Laryea $C$, et al. 3.6 million neonatal deaths - what is progressing and what is not? Semin Perinatol. 2010;34:371-386.

3. Dayyabu AL, Murtala L, Grünebaum A, et al. Midwife-assisted planned home birth: an essential component of improving the safety of childbirth in Sub-Saharan Africa. J Perinat Med. 2018;47(1):16-21.

4. UNICEF. State of the world children. New York; 2016.

5. Owusu BA, Lim A, Makaje N, et al. Neonatal mortality at the neonatal unit: the situation at a teaching hospital in Ghana. Afr Health Sci. 2018;18(2):369-377.

6. Ndombo PK, Ekei QM, Tochie JN, et al. A cohort analysis of neonatal hospital mortality rate and predictors of neonatal mortality in a suburban hospital of Cameroon. Ital J Pediatr. 2017;43(1):52. http://doi. org/10.1186/s13052-017-0369-5

7. Mukhtar-Yola M, Iliyasu Z. A review of neonatal morbidity and mortality in Aminu Kano Teaching Hospital, Northern Nigeria. Trop Doct. 2007;37(3):130-132.

8. Omoigberale Al, Sadoh WE, Nwaneri DU. A 4-year review of neonatal outcome at the University of Benin Teaching Hospital, Benin-City. Niger J Clin Pract. 2010;13(3):321-325.

9. Okechukwu AA, Achonwa A. Morbidity and mortality pattern of admissions into the Special Care Baby Unit of University of Abuja Teaching Hospital, Gwagwalada, Nigeria. Niger J Clin Pract. 2009;12 (4):389-394.

10. Nahar J, Zabeen B, Akhter S, et al. Neonatal morbidity and mortality pattern in the Special Care Baby Unit of BIRDEM. Ibrahim Med Coll J. 2009;1(2):1-4.

11. Shabbir $\mathrm{H}$. Neonatal morbidity and mortality pattern in a Tertiary Care Neonatal Unit of a Teaching Hospital. Ann Pak Inst Med Sci. 2014;10(1):7-11.

12. Ravikumar SA, Harikrishnan E, Elayaraja K, et al. Morbidity and mortality profile of neonates in a tertiary care centre in Tamil Nadu: a study from south India. Int J COntemp Pediatr. 2018;5(2):377-382.

13. Ogunfowora OB, Ogunlesi TA, Fetuga MB, et al. Clinical manifestations and outcome of hospitalized babies with birth asphyxia in Sagamu. Niger J Paediatr. 2009;35:12-18.

14. Ekwochi U, Ndu IK, Nwokoye IC, et al. Pattern of morbidity and mortality of newborns admitted into the Sick and Special Care Baby Unit of Enugu State University Teaching Hospital, Enugu State. Niger J Clin Pract. 2014;17(3):346-351.

15. Ogunlesi TA, Dedeke IOF, Adekanmbi AF, et al. The incidence and outcome of bilirubin encephalopathy in Nigeria: a bi-centre study. Niger J Med. 2007;16:354-359.

16. Ekwochi U, Asinobi N, Osuorah CD, et al. Incidence and predictors of mortality among newborns with perinatal asphyxia: a 4-year prospective study of newborns delivered in Health Care Facilities in Enugu, South-East, Nigeria. Clin Med Insights Pediatr. 2017;11:117955651774664.

17. Owa JA, Ogunlesi TA. Why we are still doing so many exchange blood transfusions for neonatal jaundice in Nigeria. World J Paediatr. 2009;5:51-55.

18. Ogunlesi TA, Ogunlesi FB. Family socio-demographic factors and maternal obstetric factors influencing appropriate health care seeking behaviour for neonatal jaundice in Sagamu, Nigeria. Matern Child Health J. 2012;16:677-684. 
19. Olusanya BO, Ogunlesi TA, Slusher TM. Why is kernicterus still a major cause of death and disability in low-income and middle-income countries? Arch Dis Child. 2014;99:1117-1121.

20. Mabogunje CA, Olaifa SM, Olusanya BO. Facility-based constraints to exchange transfusion for nenonatal hyperbilirubinaemia in resourcelimited settings. World J Clin Pediatr. 2016;5(2):182-190.

21. Ayeni VA, Oladipo AO, Ogunlesi TA, et al. Childhood morbidity and mortality at the Olabisi Onabanjo University Teaching Hospital, Sagamu: has anything changed? Int J Multidisc Res. 2012;5(1\&2):15-20.

22. Ogunfowora OB, Ogunlesi TA. Hypoxic ischaemic encephalopathy among asphyxiated Nigerian newborns. Niger Hosp Pract. 2011;7:70-76.

23. Johnson L, Brown AK, Bhutani VK. BIND: a clinical score for bilirubin induced neurologic dysfunction in newborns. Pediatr (Suppl). 1999;104:746

24. Sarnat HB, Sarnat MS. Neonatal encephalopathy following fetal distress. A clinical and electroencephalographic study. Arch Neurol. 1976;33(10):696-705.

25. Ogunlesi TA, Dedeke IOF, Kuponiyi OT. Socio-economic classification of children attending specialist health facilities in Ogun State. Niger Med Pract. 2008;54:21-25.

26. Oyedeji GA, Oyedeji OA, Ajibola AJ. The association between social disadvantage and morbidity in hospitalized children. Niger J Paediatr. 2002;29:5-10.

27. Eke CB, Ezomike UO, Chukwu BF, et al. Pattern of neonatal mortality in a Tertiary Health facility in Umuahia, South East, Nigeria. Int J Trop Dis Health. 2014;4(2):136-146.

28. Egharevba OI, Kayode-Adedeji BO, Alikah SO. Perinatal asphyxia in a rural Nigerian hospital: incidence and determinants of early outcome. J Neo Perinat Med. 2018;11(2):179-183.

29. Olusanya BO, Ogunlesi TA, Kumar P, et al. Management of late preterm and term infants with hyperbilirubinaemia in resource-constrained settings. BMC Pediatr. 2015;15(1):39.
30. Perez K, Patterson J, Hinshaw J, et al. Essential care for every baby: improving compliance with newborn care practices in rural Nicaragua. BMC Pregnancy Childbirth. 2018;18:371.

31. Sadoh AE, Ogungbe RO. Multiple fracture and iatrogenic burns in a newborn due to unskilled delivery: a case report. Afr J Reprod Health. 2008;12(3):197-206.

32. Ariff S, Soofi SB, Sadiq K, et al. Evaluation of health workforce competence in maternal and neonatal issues in public health sector of Pakistan: an assessment of their training needs. BMC Health Services Res. 2010;10:319.

33. Miller T, Smith $H$. Establishment of partnership with traditional birth attendants for improved maternal and newborn health: a review of factors influencing implementation. BMC Pregnancy Childbirth. 2017; 17:365.

34. Iskander I, Gamaleldin R, El Houchhi S, et al. Serum bilirubin and bilirubin-albumin ratio as predictors of bilirubin encephalopathy. Pediatrics. 2014;134:e1330-e1339.

35. Pálsdóttir K, Thórkelsson T, Hardardóttir H, et al. Birth asphyxia, neoneatal risk factors for Hypoxic-Ischaemic Encephalopathy. Laeknabladid. 2007;93(10):669-673.

36. Abiodun MT, Oluwafemi RO. Spectrum and outcome of neonatal emergencies seen in a free health-care program in South-western Nigeria. Niger J Clin Pract. 2017;20(3):283-289.

37. Ogunfowora OB, Daniel OJ. Neonatal jaundice and its management knowledge, attitude and practice of community health workers in Nigeria. BMC Public Health. 2006;6:19.

38. Orimadegun AE, Ojebiyi AO. Primary health workers' knowledge and practices relating to neonatal jaundice in Ibadan, Nigeria. Afr J Prm Health Care Fam Med. 2017;9(1):a1081.

39. Neogi S, Sharma J, Chauhan M, et al. Care of newborn in the community and at home. J Perinatol. 2016;36:S13-S17.

Received: 3-02-2019 Accepted: 21-05-2019 